\title{
DYNAMIC NON-LINEAR MODEL OF A SWITCHED RELUCTANCE MACHINE FOR OPERATION AS MOTOR/GENERATOR
}

\author{
G. G. Sotelo ${ }^{1}$, M. R. Ribeiro ${ }^{2}$, M. El-Mann², L. G. B. Rolim² ${ }^{2}$ J. L. da Silva Neto², \\ R. de Andrade $\mathrm{Jr}^{2}$, A. C. Ferreira ${ }^{2}$, R. M. Stephan ${ }^{2}$, W. I Suemitsu ${ }^{2}$ \\ ${ }^{1}$ UFF - TEE: R. Passo da Pátria, 156, Bl. D, CEP 24210-240, Niterói, RJ - Brasil \\ ${ }^{2}$ UFRJ - DEE/PEE: CP. 68504, CEP 21945-970, Rio de Janeiro, RJ - Brasil \\ email: ggsotelo@gmail.com, marceloraprib@yahoo.com.br, el_mann@ig.com.br, rolim@coe.ufrj.br, \\ luizneto@lif.coppe.ufrj.br, randrade@dee.ufrj.br, ferreira@coep.ufrj.br, richard@dee.ufrj.br, walter@ct.ufrj.br
}

\begin{abstract}
This paper presents a dynamic model successfully applied to simulate the operation of a switched reluctance machine. The model takes nonlinearity into account inserting machine parameters and properties as tabulated data. Part of the information was obtained by the method of finite element simulation. The power electronic converter and its control circuits are included as controlled sources in the simulation model. Finally, simulation results are compared with measurements on a laboratory prototype, in order to validate the proposed model.
\end{abstract}

Keywords - dynamic simulation model, Finite Element Method, PSCAD/EMTDC, switched reluctance machine.

\section{INTRODUCTION}

Cost reduction of power electronic converters based on solid-state devices [1-3] motivates the use of nonconventional electrical machines in several applications [45]. One of these machines is the Switched Reluctance Machine (SRM) [6] which needs a simple power electronic converter to operate. If only stator and rotor are considered, the manufacturing cost of a SRM is smaller than the cost of induction machines. The SRM operation is very simple, and it is based on the minimum reluctance principle, where both stator and rotor have salient poles.

SRMs have received attention regarding design and control [6]. Some papers describe the SRM operating as a motor/generator [7-8]. Another work presents the increase of the system efficiency, where a battery supplies (and is charged) by a SRM [9]. The SRM was also proposed as a motor/generator for a flywheel energy storage system [1012]. Some papers present the application of a vehicle driven by a SRM [13] with high efficiency. In all these examples, an accurate and precise model to simulate the SRM would be useful.

The main advantages of a SRM drive are:

- fault tolerance, since the machine is very robust;

- low production and maintenance cost;

- high efficiency;

- high energy density;

- operation at very wide speed ranges from zero up to several thousand rpm.

Manuscript received on 29/04/2009. Revised on 08/10/2009 and 08/01/2010 Accepted by recommendation of the Editor Fernando L. M. Antunes.
In recent years, several models to simulate the SRM were presented in the literature [14-21], adopting different techniques to include the non-linearity. Dynamic models based on tabulated data, using look-up tables, may present good agreement between measured and simulated results [15-16]. The present paper presents all steps necessary to simulate the dynamic behavior of a SRM as motor or generator, including: machine geometry design using a finite element method (FEM), prototype development, machine non-linear modeling and validation with experimental results. The dynamic model for the SRM was implemented in the PSCAD/EMTDC [19], using tabulated data of a $6 / 4$ SRM. These tabulated data were obtained with the help of magnetostatic simulations based on the FEM [23-24], using a commercial program. The FEM results were compared with measurements in a laboratory prototype and are presented in Section II. The dynamic model of one machine phase is presented in section III. This model also includes a bidirectional power electronic converter and is able to simulate the machine operating as a motor/generator. The control and power electronic circuits of the SRM driver are described in section IV. Therefore, dynamic simulations can be used to analyze the SRM and evaluate its performance. The key aspect of the presented model is that it can be implemented in most power system or power electronic simulation programs. Another advantage of this model is the facility to simulate machines having different geometries (just changing the stored data) and the portability of the program code (written in $\mathrm{C}++$ language) for a digital signal processor (DSP) platform as presented in section V. Finally, some simulations are presented and compared with tests in a laboratory prototype in section VI, in order to validate the model.

\section{SRM CHARACTERISTICS, PARAMETERS AND STATIC RESULTS}

This section presents some SRM properties and characteristics that can be applied to develop the dynamic model to simulate the SRM and the power electronic converter. The SRM presented here is based in a $6 / 4$ poles machine, whose constructive parameters are presented in Figure 1.

When the coil of some phase of the SRM is excited, forces are developed over the magnetic circuit that tend to bring the rotor to the position where the reluctance reaches a minimum value, as seen from the energized coil. This position is known as the aligned position of the rotor, and the coil 


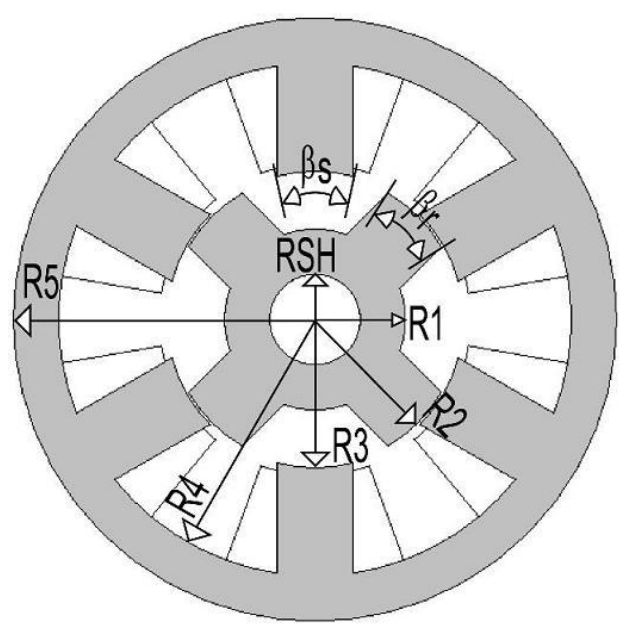

Fig. 1. 6/4 SRM and constructive parameters.

inductance reaches a maximum value. If this phase is switched off and the next one is switched on slightly before this position is reached, continuous movement of the rotor can be achieved. The torque at the aligned and at the completely un-aligned positions is null. At any other position, there is a torque different from zero.

The values of the parameters shown in Figure 1, for the prototype used in this work, are:

$\mathrm{RSH}=12.5 \mathrm{~mm}$,

$\mathrm{R} 1=24.0 \mathrm{~mm}$,

$\mathrm{R} 2=36.0 \mathrm{~mm}$,

$\mathrm{R} 3=36.5 \mathrm{~mm}$,

$\mathrm{R} 4=55.5 \mathrm{~mm}$,

$\mathrm{R} 5=67.5 \mathrm{~mm}$,

$\beta \mathrm{r}=36^{\circ}$,

$\beta \mathrm{s}=33^{\circ}$,

$\mathrm{N}=70$ turns per pole and

$\mathrm{L}_{\mathrm{Fe}}=40 \mathrm{~mm}$ that represents the stack length.

From the parameters presented above, it is possible to calculate several properties that can be used for practical purpose. Here, 2D FEM magnetostatic simulations were used to get the inductance and torque data as a function of position and current. The results are presented in Figures 2 and 3, respectively.

If the applied current in the coil of the SRM increases, the magnetic circuit starts to saturate. As a consequence of this fact, the inductance of the coil is reduced and the system

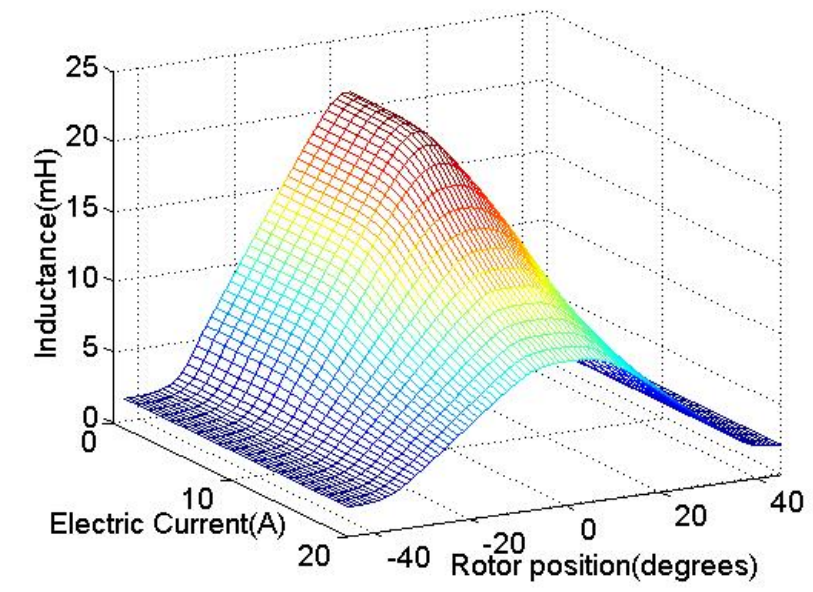

Fig. 2. Inductance data obtained from 2D FEM simulations.

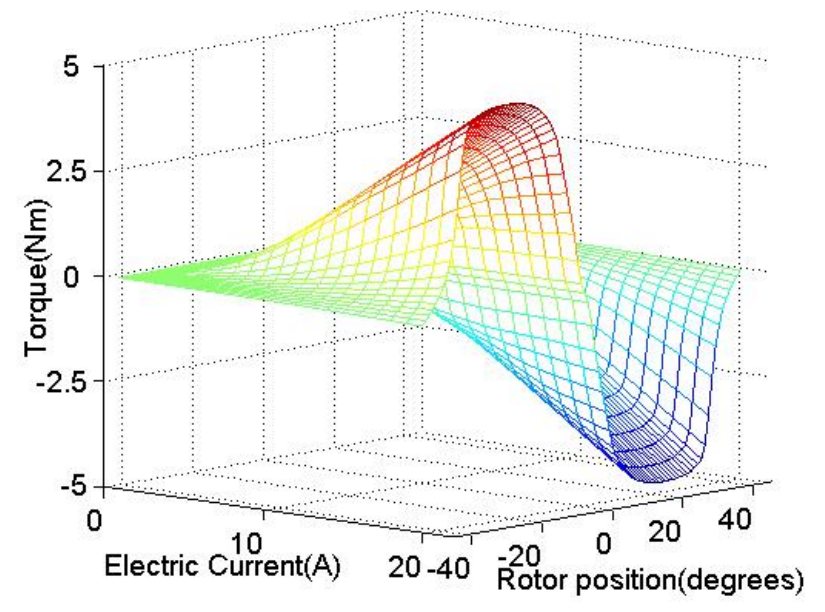

Fig. 3. Electromagnetic torque obtained from 2D FEM simulations.

becomes very non-linear. This condition is illustrated in Figure 2.

In the FEM virtual prototype, the DC magnetization curve of the ferromagnetic material was introduced in the program to consider the material saturation in the solution.

The simulated torque data was compared to measurements made into the laboratory prototype for four different current values (5, 10, 15 and 20 Amperes), as presented in Figure 4. As the current is increased, some divergence in the simulated and measured results appears. This divergence may be attributed to the lack of information about the magnetic properties of the core that could not be obtained with the SRM manufacturer. For this case, a commercial magnetization curve SAE-1010 was attributed to the SRM during the simulations. Even for different characteristics of simulated and the prototype ferromagnetic materials, the maximum discrepancy between simulated and measured results in the worse situation was smaller than $15 \%$.

Symmetry of the magnetic circuit allows for nearly null mutual flux linkage, even under saturated conditions. As a result, the contribution of each phase for torque production is mainly defined by the self-inductance profile of that phase. The electromagnetic torque can be generally obtained by the co-energy as shown in (1), where $T_{e}\left(\theta_{r}, i_{L}\right)$ is the electromagnetic torque, $\theta_{r}$ is the rotor angular position, $W$ is the co-energy and $i$ is the coil current. The electromagnetic torque produced by one single coil is then given by (2), where $\lambda$ is the total flux linked to the coil.

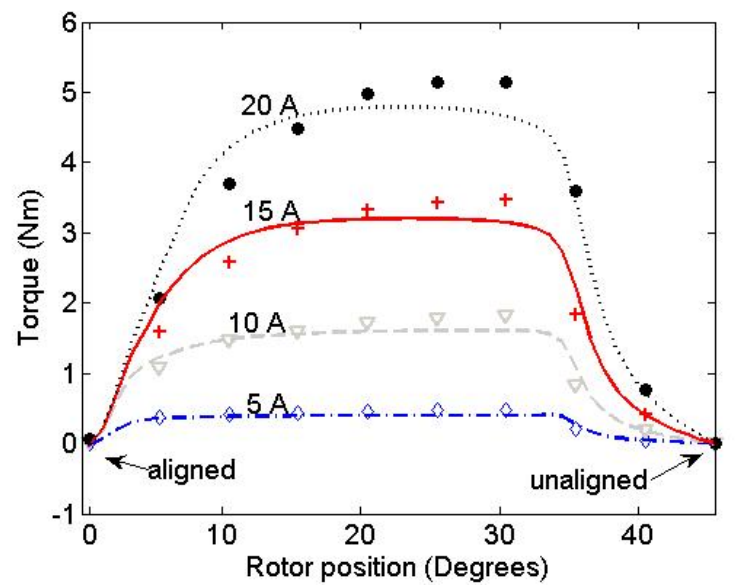

Fig. 4. Measured (dots) and FEM simulated (traces) torque data. 


$$
\begin{aligned}
T_{e}(i) & =\left(\frac{\partial W\left(\theta_{r}\right)}{\partial \theta_{r}}\right)_{i=c t e}, \\
T_{e}\left(\theta_{r}, i_{L}\right) & =\frac{\partial}{\partial \theta_{r}}\left[\int_{0}^{i} \lambda\left(\theta_{r}, i_{L}\right) d i\right] .
\end{aligned}
$$

If the saturation in the magnetic circuit is not considered, the inductance varies linearly with the rotor angular position (Figure 2 for small currents). In this situation, it is possible to see from (2) and Figure 4, that the machine torque is constant if a constant current is applied to the coil. Figure 5 can better illustrate this situation, for an ideal situation with stator and rotor poles superposition (continuous trace) and without stator and rotor poles superposition (dashed trace).

The SRM can operate as a motor or as a generator. Due to the fact that the operating principle of the SRM is based on the minimum reluctance, the algebraic sign of the produced torque does not depend on the sense of current flow through the phase windings. Actually the torque sign depends only on the relative position between rotor and stator poles, at a given instant when current is flowing. As depicted in Figure 6, if the current is flowing in a phase coil before a rotor pole pair gets aligned to the coil poles (along the sense of rotation), the produced torque will be in the same sense as the rotation (motoring torque). Conversely, if current flows after the aligned position has been reached, braking or generating torque will be produced. Therefore, the current controller must ensure that the current pulses applied to each phase occur before or after the aligned position, according to the algebraic sign of the current reference. The pulse amplitude should be thus controlled only according to the absolute value of the current reference.

\section{DYNAMIC EQUATIONS AND MODEL OF SRM}

Since the relationship between the electromagnetic torque $T_{e}\left(\theta_{r}, i_{L}\right)$ and the phase inductance $L\left(\theta_{r}, i_{L}\right)$ with the rotor angle and the phase current are strongly non-linear (as observed on Figures 2 and 3), the development of an accurate model

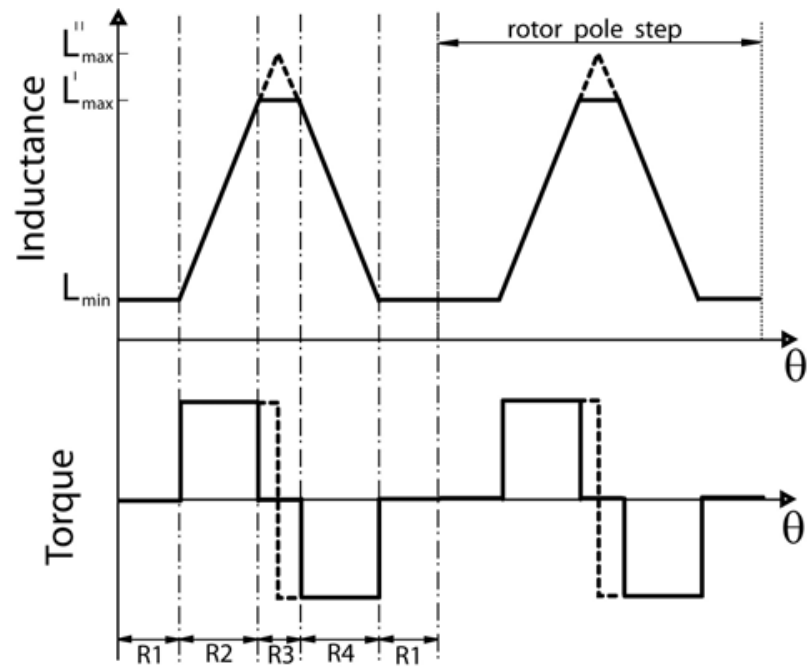

Fig. 5. Ideal one phase torque and inductance for non-saturated SRM supplied by a constant current. Continuous trace - rotor and stator poles with some superposition. Dashed trace - rotor and stator poles without superposition.

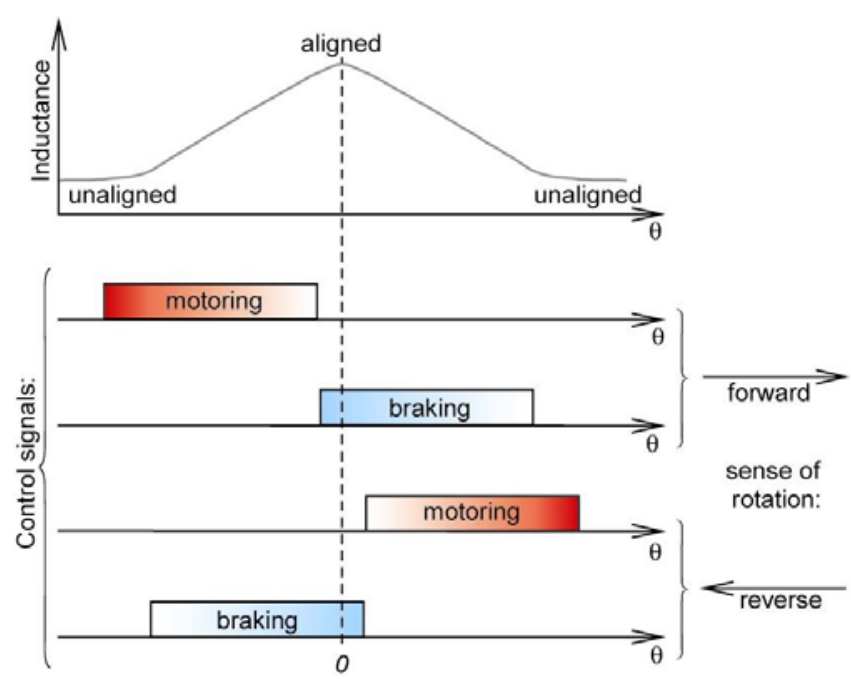

Fig. 6. Possible operation modes of a SRM.

based only on analytical relations is not possible. For this reason, the methodology proposed here is to use some tabulated data $T_{e}\left(\theta_{r}, i_{L}\right)$ and flux linkage $\lambda\left(\theta_{r}, i_{L}\right)$ of the machine. From the dynamic of its electric circuit, one SRM phase can be represented by the following equation:

$$
V=r_{s} \cdot i_{L}+\frac{d \lambda\left(\theta_{r}, i_{L}\right)}{d t},
$$

where $V$ is the coil terminal voltage, $r_{s}$ is the coil resistance and $i_{L}$ is the current flowing through the coil. To complete the modeling, it is still necessary to introduce the motion equation of the rotor:

$$
J \cdot \frac{d^{2} \theta_{r}}{d t^{2}}=T_{e}\left(\theta_{r}, i_{L}\right)-T_{m}
$$

where $J$ is the SRM rotor's moment of inertia, $T_{m}$ is the sum of load opposing torque and bearing mechanical losses torque. Equations (3) and (4) can be used to model the SRM.

The tabulated data of $T_{e}\left(\theta_{r}, i_{L}\right)$ and $L\left(\theta_{r}, i_{L}\right)$ are then used directly in the time solution of the electrical and mechanical differential equations (3) and (4). From the $L\left(\theta_{r}, i_{L}\right)$ tabulated data, $\lambda\left(\theta_{r}, i_{L}\right)$ was found and manipulated in such a way that the $i_{L}\left(\theta_{r}, \lambda\right)$ inverse relation could be produced. This result is presented in Figure 7.

Modeling inductive non-linear relations involving rotating

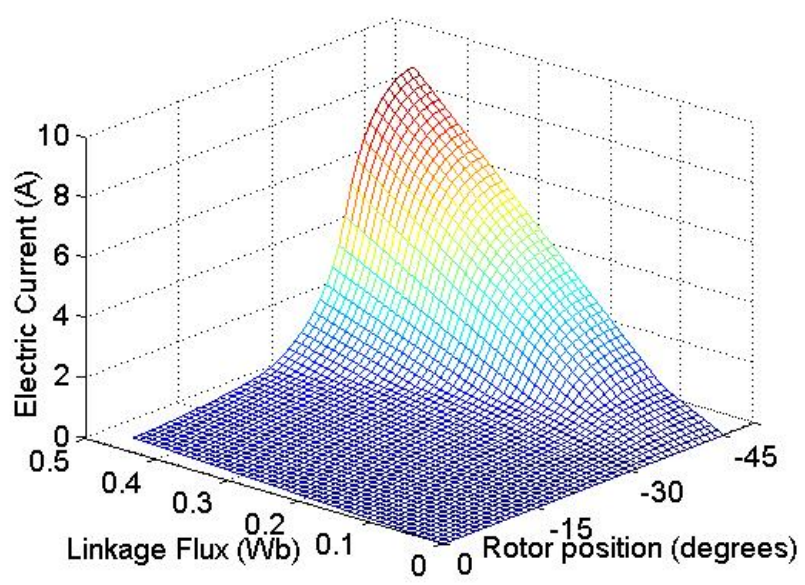

Fig. 7. Current as a function of rotor position and linkage flux. 
magnetic circuits is not apparent. With the purpose of addressing this problem, let us consider the fundamental $V-i$ relationship in an inductance:

$$
\begin{gathered}
v_{L}(t)=L \frac{d i_{L}(t)}{d t} \\
i_{L}(t)=\frac{1}{L} \int v_{L}(t) d t+i_{L}(0)
\end{gathered}
$$

Equation (6) is obtained by solving (5) for $i_{L}(t)$. This means that an inductance can be modeled as a current source controlled by the integral of the voltage between its terminals, or equivalently, by the total magnetic flux linked by the coil.

The elements involved in this modeling are common in most circuit simulation programs. The modeled inductance is inserted on the simulated circuit between two nodes (current source terminals). The phase inductance has to be modeled as a current source controlled by the total flux linked to the coil and the rotor position, as shown in Figure 8.

The relationships $T_{e}\left(\theta_{r}, i_{L}\right)$ and $i_{L}\left(\theta_{r}, \lambda\right)$ are then integrated into standard 2-D lookup-table blocks, which use online linear interpolation to obtain intermediate values, when needed. This model is very exact and can reproduce accurately the dynamics of the SRM when driven by a pulsewidth modulation (PWM) power converter.

\section{POWER ELECTRONIC DRIVER}

In this section the power electronic converters used to drive the SRM and to connect the machine with the electric grid are presented in Figure 9. There are two power electronic converters connected by a DC link, as suggested in Figure 10.a. Both of the converters are bidirectional in the sense of energy flow. The grid side converter is a conventional three-phase converter in a full-bridge IGBT configuration with PWM control. This converter works as a rectifier or as a inverter, depending on the direction of energy flow during the flywheel operation. When the critical load is connected to the DC link, this converter is turned off during the regenerating period. An asymmetrical bridge was used as the power circuit responsible for the current control of each phase of the SRM machine. The main feature of this topology is the two-quadrant operation, allowing for reversibility of the applied voltage with unidirectional

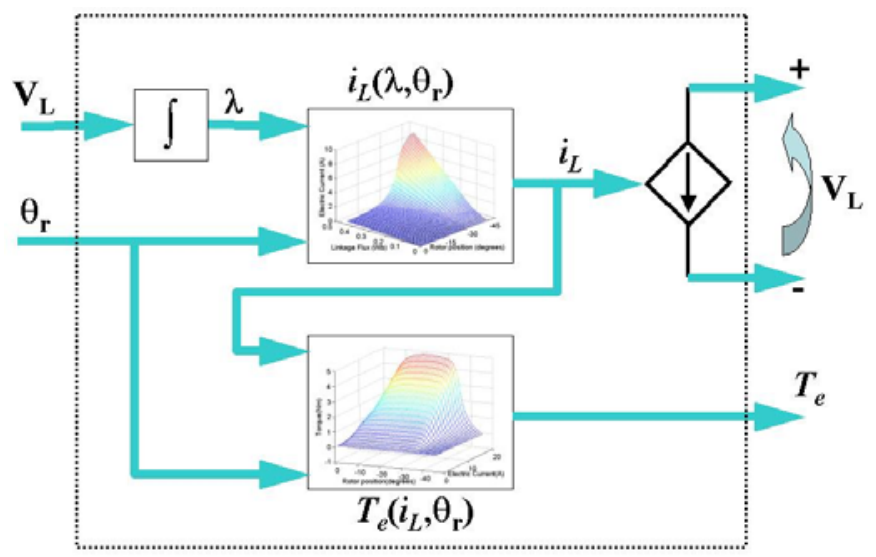

Fig. 8. Model of one phase SRM inductance.

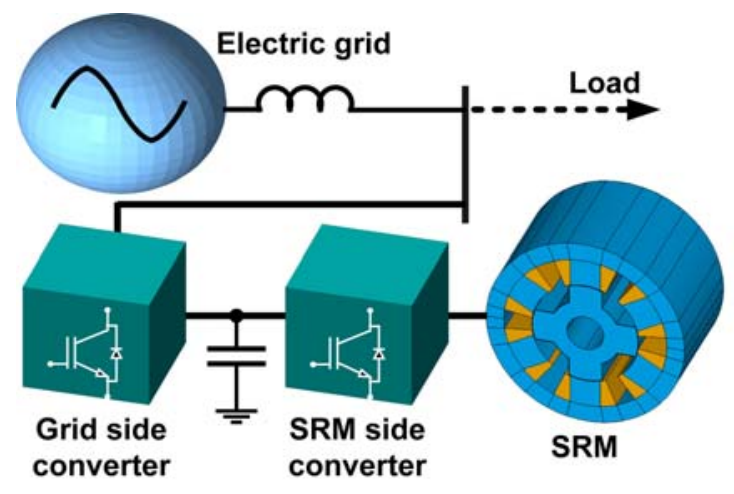

Fig. 9. Diagram with the main components.

current. Since the direction of the magnetic flux does not influence the inductance profile along the angular position, the polarity of the circulating current is not important. However, a bipolar voltage circuit is crucial for fast current extinction in motoring operation, and for the correct current control in the regenerating mode.

For the current synthesis the strategy adopted is the PWM control with hysteresis band. The phase current tracks its reference inside a tolerance band, in a closed-loop operation. According to the required energy flow direction, the switching sequence determines three different states described above for the power circuit, as presented in Figure 10.b.

STATE 1 is characterized by the conduction of IGBTs $T_{1}$ and $\mathrm{T}_{2}$. In this case, the DC link voltage is directly applied above the SRM coil, forcing the current to circulate in the positive direction. Therefore, the energy flows from the DC link to the machine.

During STATE $2 \mathrm{~T}_{2}$ and $\mathrm{D}_{2}$ are conducting and the current can fall freely if the angular interval of conduction determines a positive torque for positive angular speed. Otherwise, if the speed is positive and the torque is negative, the phase current will tend to grow due to the negative sign of the factor $\frac{\partial \lambda}{\partial \theta} \frac{d \theta}{d t}$. This term can be viewed as a "speed voltage" obtained from the expansion of $\frac{d \lambda\left(\theta_{r}, i_{L}\right)}{d t}$ in (3).

For STATE 3 only the diodes $\mathrm{D}_{1}$ e $\mathrm{D}_{2}$ are conducting and a negative voltage $\left(-V_{D C}\right)$ is applied over the stator phase, forcing the current to decrease. Under this condition, the

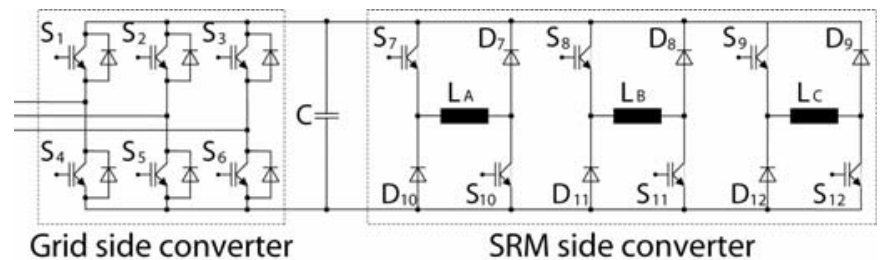

(a)

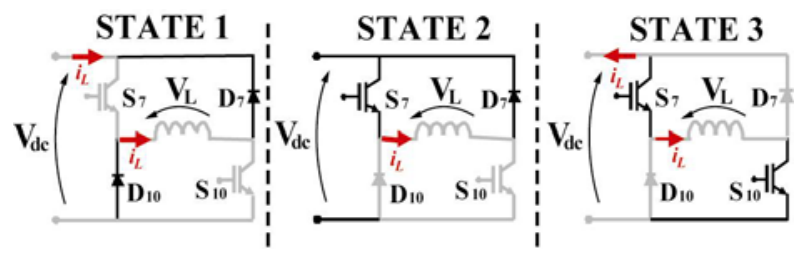

(b)

Fig. 10. (a) Power electronic converters used to drive the SRM. (b) Three operating states of the SRM side converter. 
converter injects current into the DC link regenerating energy. In all three states the current flows through the stator phase in the same direction. Since each state ultimately define the voltage applied to the stator phases, the behavior of the power converter can be modeled by switching functions. This approach is particularly interesting to be employed in some simulation software having convergence problems or inherently slow execution rate. Modeling static switches involves determining the zero-crossing instants, which can be very time-consuming, depending on the algorithm for solving non-linear differential equations. Therefore, it is possible to model the converter using voltage sources controlled by switching functions. For the SRM drive, one can define the function $\boldsymbol{p}$ that can assume values 1 , 0 or -1 according to states 1,2 and 3, respectively. This result in the following equations for voltage applied to one stator phase $V_{L}$ and DC link total current $I_{D C}$ :

$$
\begin{gathered}
V_{L}=\boldsymbol{p} V_{D C}+(\boldsymbol{p}-1) V_{F}-(1+\boldsymbol{p}) V_{C E s a t}, \\
I_{D C}=\boldsymbol{p}_{1} I_{L A}+\boldsymbol{p}_{2} I_{L B}+\boldsymbol{p}_{3} I_{L C},
\end{gathered}
$$

where $V_{F}$ is the voltages across the diodes and $V_{C E s a t}$ is the voltage across the solid state switch and $I_{L A}, I_{L B}$ and $I_{L C}$ are the stator currents of phases A, B and C, respectively.

\section{APPLICATION OF THE MODEL TO TEST THE SYSTEM PERFORMANCE}

The development of new control strategies relies heavily on the possibility of working with virtual prototypes, which allow testing several design optimizations without actually building them. Therefore, there is a need for models that correctly represent all the system components.

As described in the last section, the power electronics circuit consists of two converters. To drive the SRM a halfbridge IGBT-based converter is used, allowing operation as motor or generator. The DC link is connected to the network by a bridge pulse width modulation (PWM) converter. The objective of the control operation is to determine the direction of the power flow. This is achieved by regulating the DC link voltage.

The logic for determining the operation as motor or generator of the $6 / 4 \mathrm{SRM}$ is presented by pseudo-code 1 . The current control of the machine is presented by pseudo-code 2 , using the hysteresis band strategy to control the winding current. Each stator phase conducts for approximately 30 mechanical degrees on either motoring or regenerating modes. In these pseudo-codes: $\theta_{\mathrm{ON}}, \theta_{\mathrm{OFF}}$ are the angles for, respectively, the triggering and blocking the current circulation; $i_{\mathrm{L}}$ and $i_{\text {Lref }}$ are, respectively, the measured and the reference current; $\Delta i$ is the hysteresis current band and $\omega$ is the angular speed.

Figure 11 presents the control strategy used to the SRM operating as a motor/generator for a flywheel energy storage system. Initially, the capacitor of the DC Link is charged by the grid side converter until the reference voltage is reached, and it is controlled by the voltage control loop associated to the grid side converter. Continuing the initialization process, the velocity control loop commands the SRM Converter, which set in motion the machine as a motor, accelerating the flywheel until the reference velocity is reached. Then the
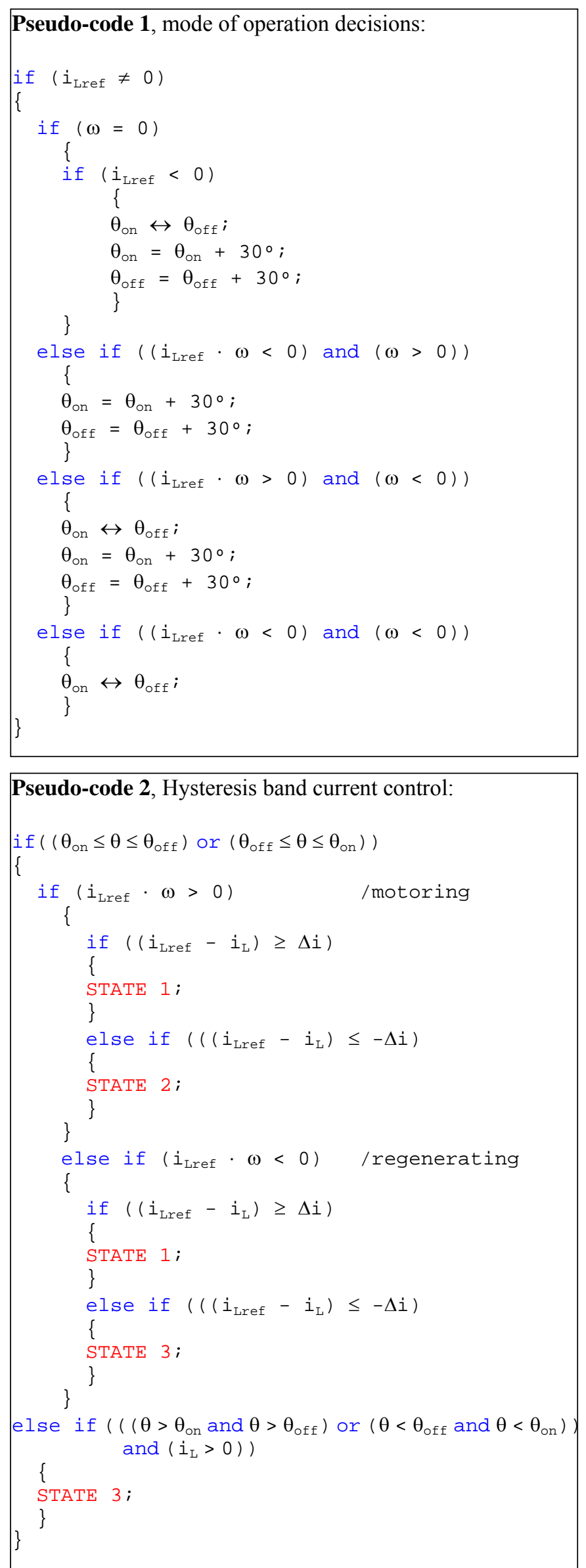


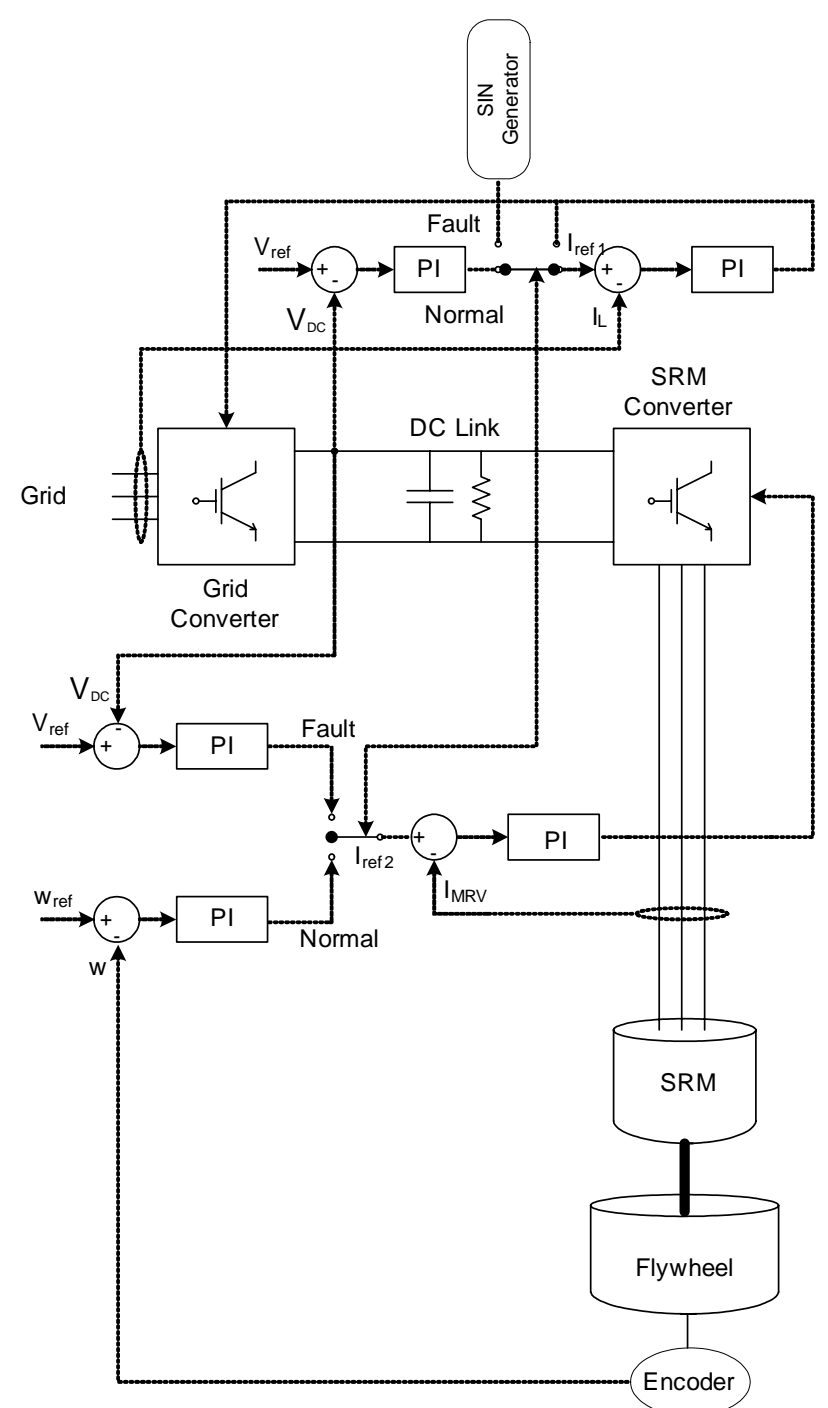

Fig. 11. Control strategy for operation as a flywheel motor/generator.

system will be ready to supply an electric load during a fault in the grid as long as there is enough kinetic energy stored in the flywheel.

During the grid fault, this kinetic energy is converted in electric energy by the SRM, which works at this moment as a generator. The control of the SRM pass from the velocity control loop, during normal operation, to the voltage control loop, during the fault operation. The voltage control is executed by a control loop associated to the SRM Converter, and the operation of the Grid Side Converter will depend on the application of this system. If the system supplies a DC load, the Grid Converter is turned off, and when supplying an AC load, this converter operates as an inverter, providing currents to the systems.

\section{SIMULATED AND MEASURED RESULTS}

This section presents some simulated and measured results using the proposed model of the SRM. The SRM model presented on section III was implemented in PSCAD/EMTDC (see Appendix for more details) [22] using the tabulated data of section II and the power electronic driver of section IV. The mode of operation decision and the current control presented in section $\mathrm{V}$ are also applied. The software is able to represent the main components affecting this interaction, namely: the SRM, the power electronics circuit, the control circuit and the mechanical system. In order to validate the model, tests were carried out in a 1.5 $\mathrm{kW}$ prototype shown in Figure 12. The nominal parameters of this machine are: speed $3600 \mathrm{rpm}$, torque $4 \mathrm{Nm}$, voltage $300 \mathrm{~V}$ and current $5 \mathrm{~A}$ rms per phase.

To control the bi-directional power electronic converter presented in Figure 13, a digital signal processor TMS320F2812 was used.

The first procedure made to compare the measured and simulated results was the operation of the SRM in the single pulse mode. The current results in one stator phase are shown in Figure 14. For this test, the machine was running in openloop at approximately $1000 \mathrm{rpm}$, with $9 \mathrm{~V}$ in the DC link, opposing to the normal closed-loop operating voltage $(>400 \mathrm{~V})$.

For the second test, a PWM and PI current control were implemented into the SRM side converter and the winding current results for one phase are compared for simulations and measurements, as shows Figure 15. During the switching time there is a correspondence between STATES 1 and 2 , when the SRM operates in motor mode and the switching between STATES 1 and 3, when the SRM operates in generator mode, as illustrated in Figure 10.b. The pulse width depends on the velocity of the SRM rotor, while the current amplitude depends on the moment of inertia $J$ of the spinning

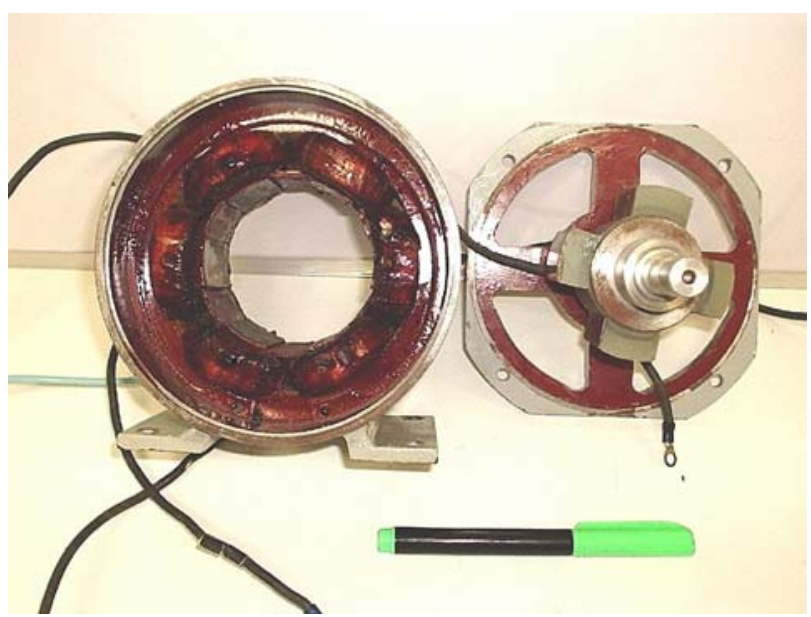

Fig. 12. Opened view of the $1.5 \mathrm{~kW}, 6 / 4$ SRM prototype.

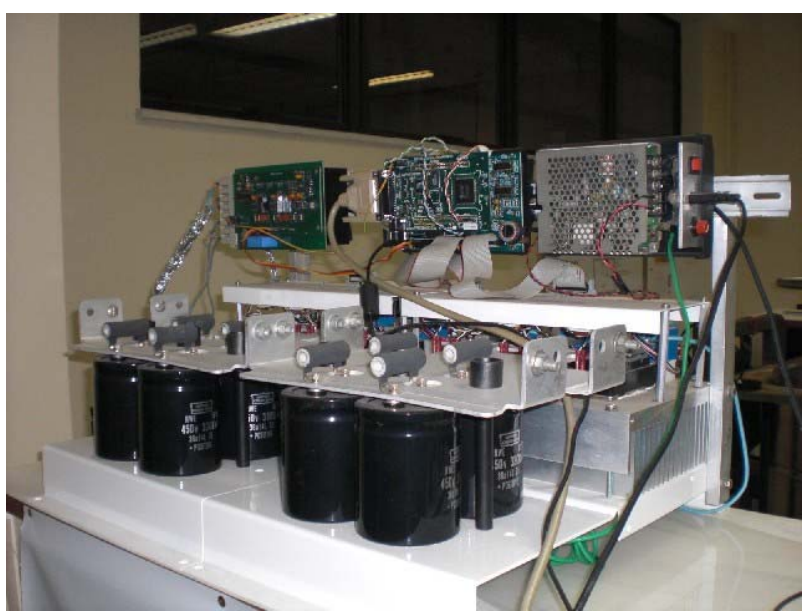

Fig. 13. Power electronic converter used to drive the SRM. 


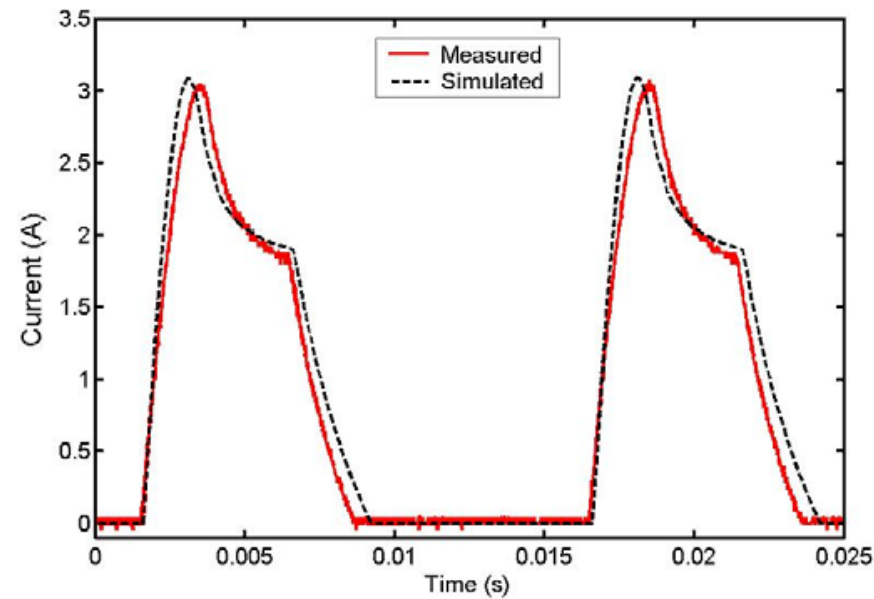

Fig. 14. Current in one stator phase in the single pulse mode.

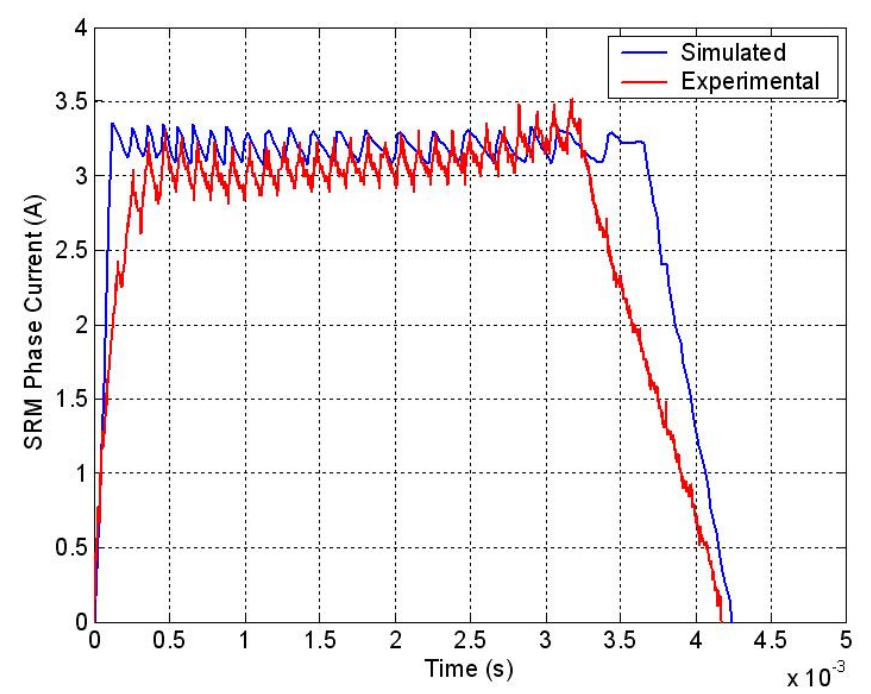

Fig. 15. SRM phase currents for PI and PWM current control.

mass (in motor mode) and the electric load (in generator mode). In both modes, the losses contribute to the SRM phase current level.

For the next test, the SRM was accelerated to a speed of $450 \mathrm{rpm}$ and, after it reaches the continuous state, the switch $\mathrm{S} 7$ on Figure 10.b is opened and the machine operation mode is changed to generator. For this situation, the rotor mechanical energy is converted to electrical energy, which is responsible to continue the critical load operating at nominal voltage level during the imposed fault. The simulated and measured speed results are presented in Figure 16. This situation illustrates the flywheel operation principle [10-11]. Between 23 and 30 seconds, approximately, there is a conversion of the mechanical energy in the electrical one. After 30 seconds, the capacitor voltage in the DC link is zero and it doesn't have enough energy to control the system. In this moment it is not possible to apply the current pulses on the SRM phases, when the rotor starts to rotate freely, without electromagnetic opposite torque.

In order to illustrate the behavior of the SRM with the electric grid, Figure 17 shows the simulated results for speed and torque curves, for a simulated fault (to open SW1) between $t=16 s$ and $t=18 \mathrm{~s}$. During this period the SRM was capable to supply a 350VA load with the energy that comes from the decelerating of the rotor. The torque curve in

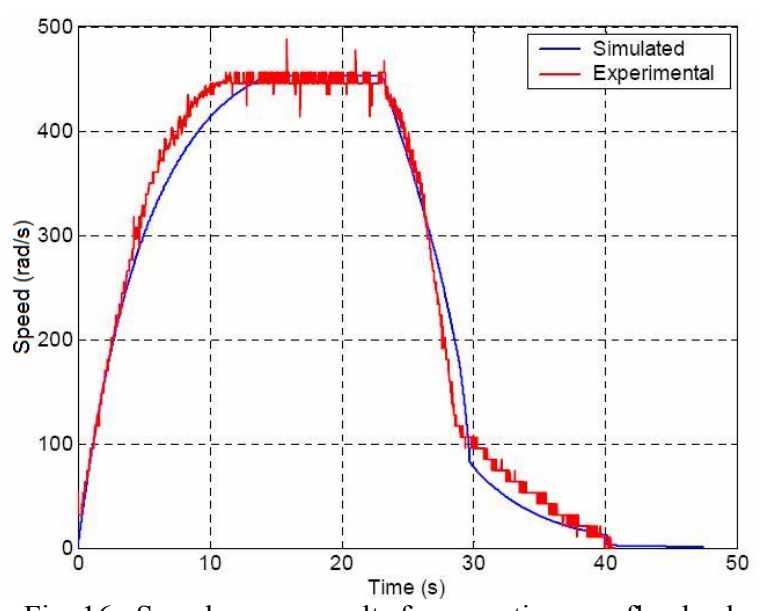

Fig. 16. Speed curves results for operation as a flywheel.

Figure 17 indicates that during the normal operation, the SRM torque is positive, and during the period of the fault, the SRM torque is negative, which is in accordance with the speed curve. As the speed decreases, the torque increases, in order to supply the load with constant power, as in the (9), where $P$ is the power and $\omega$ is angular velocity.

$$
P=T_{e} \cdot \omega \text {. }
$$

For this situation, Figure 18 shows the simulated results of the voltage in the electrical load when it is supplied by the SRM operating as a generator. When the rotor begins to supply energy to the electric load, the voltage and frequency are kept at the nominal value. A variable transformer adjusted the grid voltage before the fault in $90 \mathrm{~V}_{\text {peak }} / 60 \mathrm{~Hz}$. The grid side converter can be adjusted in the computational program by settling the amplitude modulation ratio $\left(\mathrm{m}_{\mathrm{a}}\right)$.

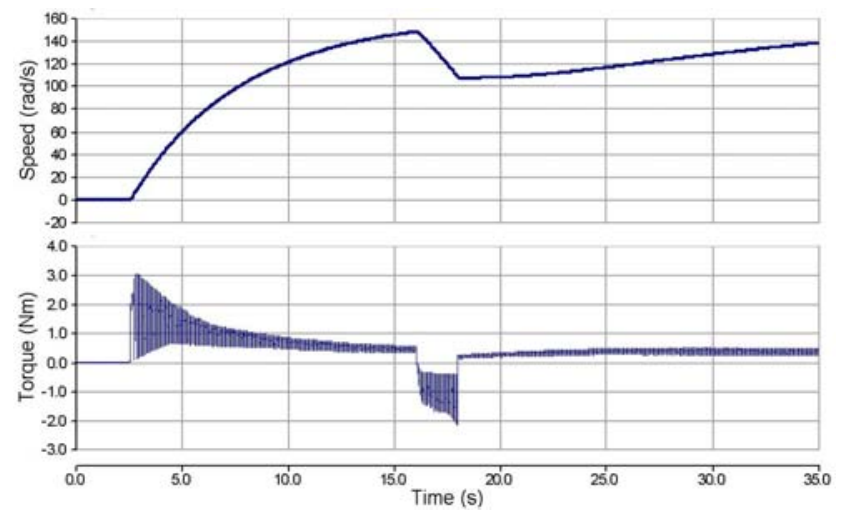

Fig. 17. SRM operating as a flywheel.

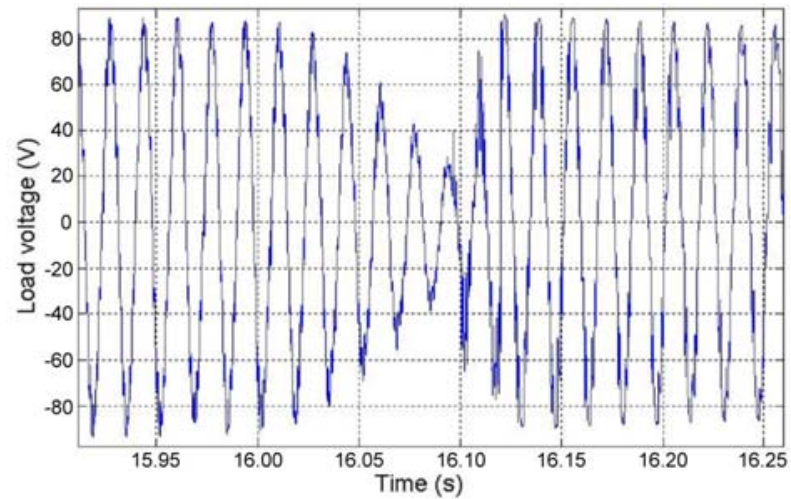

Fig. 18. Load Voltage (V) - Fault in $\mathrm{t}=16 \mathrm{~s}$. 
This condition was simulated with the PSCAD diagrams (Figures A1 and A2) shown in the Appendix. At $t=16 \mathrm{~s}$, the circuit-breakers BKA, BKB, BKC open, simulating the grid supply failure and the control loop switches are commutated. In Figure A1 the switch, which the output is Iref, changes from position $\mathrm{A}$ to $\mathrm{B}$, maintaining the $\mathrm{DC}$ voltage steady. Likewise, in Figure A2, the switch, which the output is Iamp, changes from position A to B, supplying the load with the correct magnitude of the previous sinusoidal signal. The SRM Converter Control maintains the DC voltage constant while the Grid Converter Control produces a sinusoidal waveform during the fault period.

\section{CONCLUSION}

This paper presented a dynamic model to simulate the switched reluctance machine as motor or generator, taking non-linearity into account.

The model was implemented in PSCAD/EMTDC using tabulated data obtained from FEM simulations. Simulated and measured results showed accurate agreement, validating the model. Using this model it is possible to represent correctly all the particularities of the SRM machine, and employ it in several virtual prototypes, allowing to test many control strategies and design optimizations without actually building them.

\section{APPENDIX}

The models implemented in PSCAD to simulate the SRM as motor/generator are presented in Figures A1 and A2.

The parameters used for the simulation and tests are presented at Table A1.

TABLE A1

Simulated and measured parameters adopted

\begin{tabular}{lc}
\hline Sample/Step time & $4 \mu \mathrm{s}$ \\
\hline DC Link Reference Voltage & $300 \mathrm{~V}$ \\
\hline Switching Frequency & $15 \mathrm{kHz}$ \\
\hline PI speed control gain & 0.08 \\
\hline PI speed control integral time & $10 \mathrm{sec}$ \\
\hline PI voltage control gain & 0.16 \\
\hline PI voltage control integral time & $1.6 \mathrm{sec}$ \\
\hline PLL Ki gain & 900 \\
\hline PLL Kp gain & 50 \\
\hline PI current Id control gain & 0.16 \\
\hline PI current Id control integral time & $1.6 \mathrm{sec}$ \\
\hline PI current Iq control gain & 0.16 \\
\hline PI current Iq control integral time & $1.6 \mathrm{sec}$ \\
\hline
\end{tabular}

\section{REFERENCES}

[1] M. Barnes and C. Pollock, "Power Electronic Converters for Switched Reluctance Drives", IEEE Trans. on Power Electronics, vol. 13, no. 6, 1998.

[2] J. Popović, J. A. Ferreira, M. B. Gerber, A. Konig, R. de Doncker, "Integration Technologies for High Power Density Power Electronic Converters for AC Drives", in Proc. of the International Symposium on Power Electronics,. Electrical Drives, Automation and Motion, 2006.
[3] T. G. Habetler and R. G. Harley, "Power Electronic Converter and System Control", Proc. of the IEEE, vol. 89, no. 6, 2001.

[4] I. Boldea and S. A. Nasar, Electric Drives, CRC Press, 1999.

[5] N. Mohan, Electric Drives: An Integrative Approach, Publised by MNPERE, 2003 Edition.

[6] T. J. E. Miller, "Switched Reluctance Motors and their Control", Magna Physics Publishing and Oxford Science Publications, London, UK, 1993.

[7] A. V. Radun, C. A. Ferreira and E. Richter, "TwoChannel Switched Reluctance Starter/Generator Results", IEEE Transactions on Industry Applications 34, 1026-1034, 1998.

[8] M. E. Elbuluk, M. D. Kankam, "Potential Starter/Generator Technologies for Future Aerospace Application”, IEEE AES Systems Magazine, October 1996, pp. 17-24.

[9] H. C. Chang and C. M. Liaw, "On the Front-End Converter and Its Control for a Battery Powered Switched-Reluctance Motor Drive", IEEE Trans. on Power Electronics, vol. 23, no. 4, 2008.

[10]R. de Andrade Jr. et al, "Flywheel Energy Storage System Description and Tests", IEEE Trans. on Applied Superconductivity, vol. 17, no. 2, 2007.

[11] R. de Andrade Jr. et al, "A Superconducting High-Speed Flywheel Energy Storage System", Physica $C$ : Superconductivity, vol. 408-410, pp. 930-931, 2004.

[12] R. M. Stephan, R. de Andrade Jr. and G. G. Sotelo, "Third Generation of Flywheels: A Promising Substitute to Batteries", Eletrônica de Potência, vol. 13, no. 3, pp. 171-176, August of 2008.

[13] S. Wang, Q. Zhan, Z. Ma and L. Zhou, "Implementation of a $50-\mathrm{kW}$ Four-Phase Switched Reluctance Motor Drive System for Hybrid Electric Vehicle", IEEE Trans. on Magnetics, vol. 41, no. 1, 2005.

[14] L.L.N. dos Reis, A.A.R. Coelho, O.M. Almeida and R.N.C. Almeida, "Modeling and Control of Switched Reluctance Motor Drives Based on Setpoint Relay", Eletrônica de Potência, vol. 13, no. 3, pp. 163-170, 2008.

[15]F. Soares and P. J. Costa Branco, "Simulation of a 6/4 Switched Reluctance Motor Based on Matlab/Simulink Environment", IEEE Transactions on Aerospace and Electronic Systems, Vol. 37 (3), pp. 989-1009, 2001.

[16]P. Chancharoensook and M. Rahman, "Dynamic modeling of a Four-Phase 8/6 Switched Reluctance Motor Using Current and Torque Look-Up Tables", IECON, pp. 491-496, 2002.

[17]A. K. Jain and N. Mohan, "Dynamic Modeling, Experimental Characterization, and Verification for SRM Operation With Simultaneous Two-Phase Excitation", IEEE Transactions on Industrial Electronics, vol. 53, no. 4, pp. 1238-1249, 2006.

[18] L. O. A. P. Henriques, L. G. B. Rolim, W. I. Suemitsu and Paulo J. Costa Branco "Uma Revisão das Estratégias de Redução de Ondulações de Conjugado no Motor de Relutância Chaveado", Eletrônica de Potência, vol. 8, no. 1, pp. 16-24, 2003 (in Portuguese).

[19]D. Wen, L. Deliang and C. Zhuping, "Dynamic Model and Simulation for a 6/4 Switched Reluctance Machine 
System Assisted by Maxwell SPICE and Simplorer", IEEE International Conference on Mechatronics and Automation, 2007, Harbin, China.

[20]A. K. Jain and N. Mohan, "Dynamic Modeling, Experimental Characterization, and Verification for SRM Operation With Simultaneous Two-Phase Excitation", IEEE Transactions on Industrial Electronics, vol. 53, no. 4, pp. 1238-1249, 2006.

[21]Hoang Le-Huy Patrice Brunelle, “A Versatile Nonlinear Switched Reluctance Motor Model in Simulink using Realistic and Analytical Magnetization Characteristics", Industrial Electronics Conference, art. no. 1569136, pp. 1556-1561, 2005.

[22] Manitoba HVDC Research Center Inc., EMTDC/PSCAD Simulation Manual.

[23] G. G. Sotelo, "Comparison of Switched Reluctance Machines' Structures for Using in Kinetic Energy Storage Devices", Master Degree thesis, COPPE, Federal University of Rio de Janeiro, Brazil, 2003 (in Portuguese).

[24]P. P. de Paula, W. M. da Silva, J. R. Cardoso and Sílvio I. Nabeta, "Simulacão do Desempenho de Motores e Geradores de Relutância Chaveados", Eletrônica de Potência - vol. 8, n 2, pp. 69- 77, November of 2003. (in Portuguese).

\section{BIOGRAPHIES}

Guilherme Gonçalves Sotelo received the B.Sc. degree in physics from the Federal University of Rio de Janeiro (UFRJ), Rio de Janeiro, in 2001, the M.Sc. and D.Sc. degrees were obtained in electrical engineering from the UFRJ in 2003 and 2007, respectively. He also received the the B.Sc. degree in Electrical Engineering from UFRJ in 2009. He made a Pos-Doctoral Research at LASUP/UFRJ, Rio de Janeiro, Brazil from 2007 to 2009. Actually he is Associate Professor at the Electrical Engineering Department of the Fluminense Federal University (UFF). His main interests are in the fields of applications of superconductivity, phenomenological models for superconductors and electromagnetic simulations with finite element method.

Marcelo Raposo Ribeiro received the B.Sc. degree in Electrical Engineering from the Federal University of Rio de Janeiro (UFRJ), Rio de Janeiro, in 1997 and the M.Sc. degree was obtained in Electrical Engineering from the UFRJ in 2008. Actually he is engineer of the Brazilian Navy at the Department of the Naval Projects of the Arsenal de Marinha do Rio de Janeiro. His main interests are in the fields of applications of power electronics, Flywheel Energy Storage Systems (FESS) and concurrent engineering softwares for naval applications.

Maurício El-Mann received the B.Sc. degree in Electrical Engineering from the Federal University of Rio de Janeiro (UFRJ), Rio de Janeiro, in 1997 and the M.Sc. degree was obtained in Electrical Engineering from the UFRJ in 2009. Actually he is engineer of the Brazilian Navy at the Electric Workshop of the Arsenal de Marinha do Rio de Janeiro. His main interests are in the fields of applications of power electronics and Flywheel Energy Storage Systems (FESS).

Luís Guilherme Barbosa Rolim received the B.Sc., M.Sc degrees in electrical engineering from the Universidade Federal do Rio de Janeiro (Rio de Janeiro - Brazil) in 1988 and 1993 respectively, and Ph.D in 1997 from the Technische Universitat Berlin, at Germany. He is currently an associate professor at the Department of Electrical Engineering (UFRJ - Brazil). His main interests involve Power Electronics, Switched Reluctance Drives and Soft Switching Converters.

José Luiz da Silva Neto received the B.Sc., M.Sc degrees in electrical engineering from the Universidade Federal do Rio de Janeiro (Rio de Janeiro - Brazil) in 1988 and 1993 respectively, and Ph.D. from the Université Laval (Québec Canada) in 1999. He is currently an associate professor at the Department of Electrical Engineering (UFRJ - Brazil). His main interests involve Industrial Electronics, Instrumentation, Power Electronics and Control Systems. He is been working regularly as consultant for the Brazilian Institute of Metrology (INMETRO) since 2007.

Rubens de Andrade Jr. received.the B.Sc., M.Sc and D.Sc. degree in physics from Universidade Estadual de Campinas (UNICAMP), in 1985, 1989 and 1995 respectively. Since 1999, he has been with the Department of Electrical Engineering, UFRJ. He has worked with selective surfaces for solar heaters, electrochemical alloy deposition, vortex dynamics of type II superconductors, HTS preparation and characterization (Hg-1212) and vortex dynamics of $\mathrm{Hg}$ based superconductors (Hg-1212 and Hg-1223). At moment, his main interests is in the applications of superconducting materials in power electrical systems and transportation, also he has interest in the simulation of superconducting devices.

Antônio Carlos Ferreira received the B.Sc. and M.Sc. degrees from the Federal University of Rio de Janeiro, Rio de Janeiro, Brazil, in 1987 and 1991, respectively, and the Ph.D. degree from the University of Cambridge, Cambridge, U.K., in 1997, all in Electrical Engineering. Since 1989, he has been with the Graduate School of Engineering, Federal University of Rio de Janeiro, where he is currently an Associate Professor, teaching at both under-graduate and post-graduate levels. His main interests are power system and electrical machines.

Richard Magdalena Stephan received the B.Sc. degree in electrical engineering from the Instituto Militar de Engenharia (IME), Rio de Janeiro, in 1976, the M.Sc. degree in electrical engineering from the Universidade Federal do Rio de Janeiro (UFRJ) in 1980, and the Dr.-Ing. degree in electrical engineering from Ruhr Universität Bochum, Germany, in 1985. He has an MBA degree (2005) from the Center for Scientific Enterprise, London (CSEL), on the Technology Enterprise Development. During 1977, he worked as an engineer at Furnas Centrais Elétricas, Rio de Janeiro. Since 1978, he has been with the Department of Electrical Engineering, UFRJ. He spent a sabbatical leave at 
CEPEL, the Research Center of ELETROBRAS in 1993. His main interests are in the fields of applications of superconductivity, control of electrical drives and power electronics.

Walter Issamu Suemitsu received the Electrical Engineer degree in 1975 from the Escola Politécnica da Universidade de São Paulo. He received the M.Sc. degree from COPPE - UFRJ, Brazil in 1979 and the Doctor degree from Institut National Polytechnique de Grenoble, France, in 1986, both in Electrical Engineering. He made a Pos-Doctoral Research at Laval University, Québec, Canada from 1991 to 1993. Since 1977 he has teaching and developing researches at the Electrical Engineering Departament, from Escola Politécnica, UFRJ, where he is an Associated Professor. Since 1986 he is also Associated Professor at COPPE, the Engineering Graduate School of UFRJ. At the moment he is Dean of the UFRJ Technology Center. His research interests include electrical machine drives and applications of power electronic converters on electrical drives. He is also interested on applications of Power Electronics in renewable energy systems. Dr. Suemitsu is Senior Member of IEEE.

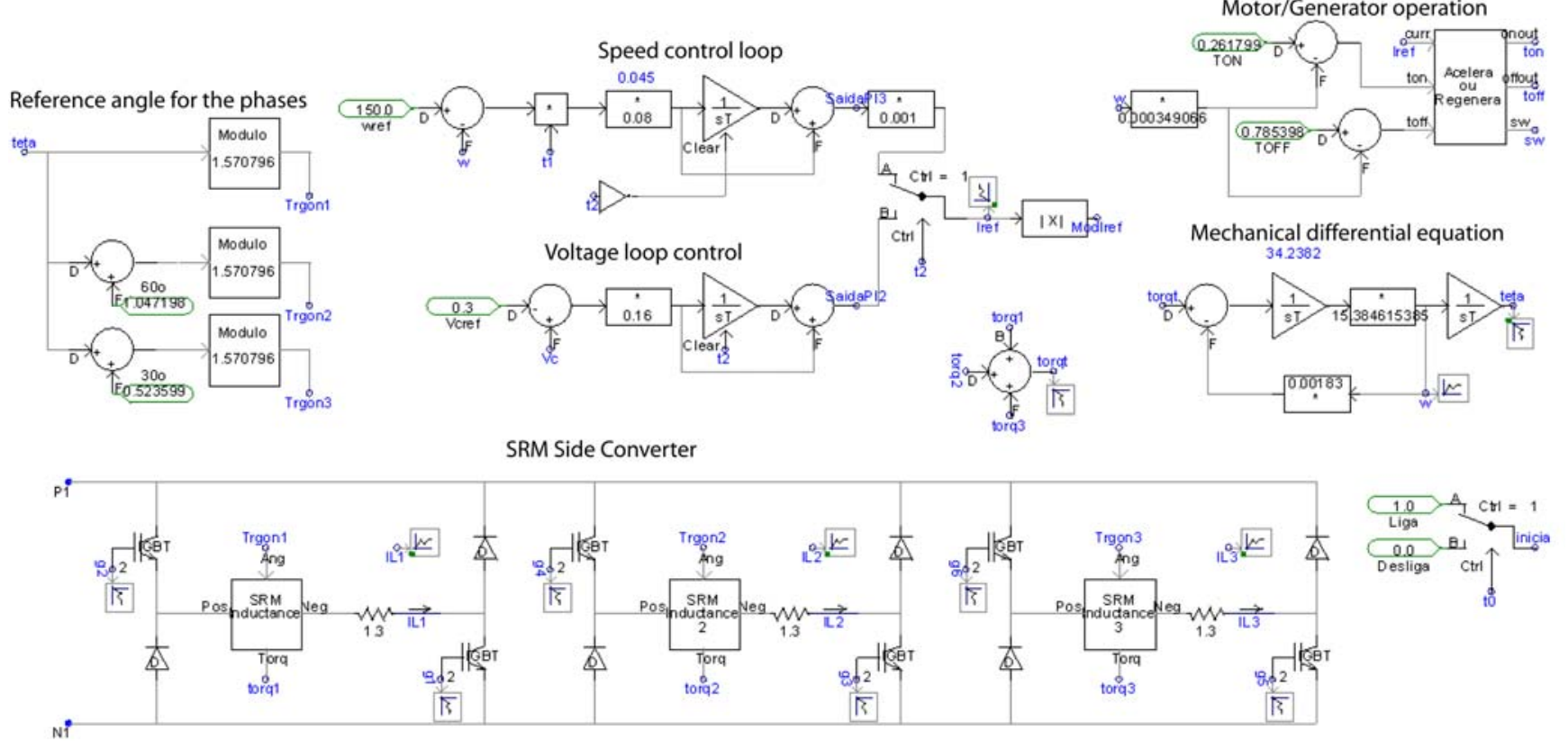

Fig. A1. PSCAD model of the SRM side converter, this control and the mechanical dynamics. SRM inductance as given in Figure 8.

Phase locked loop
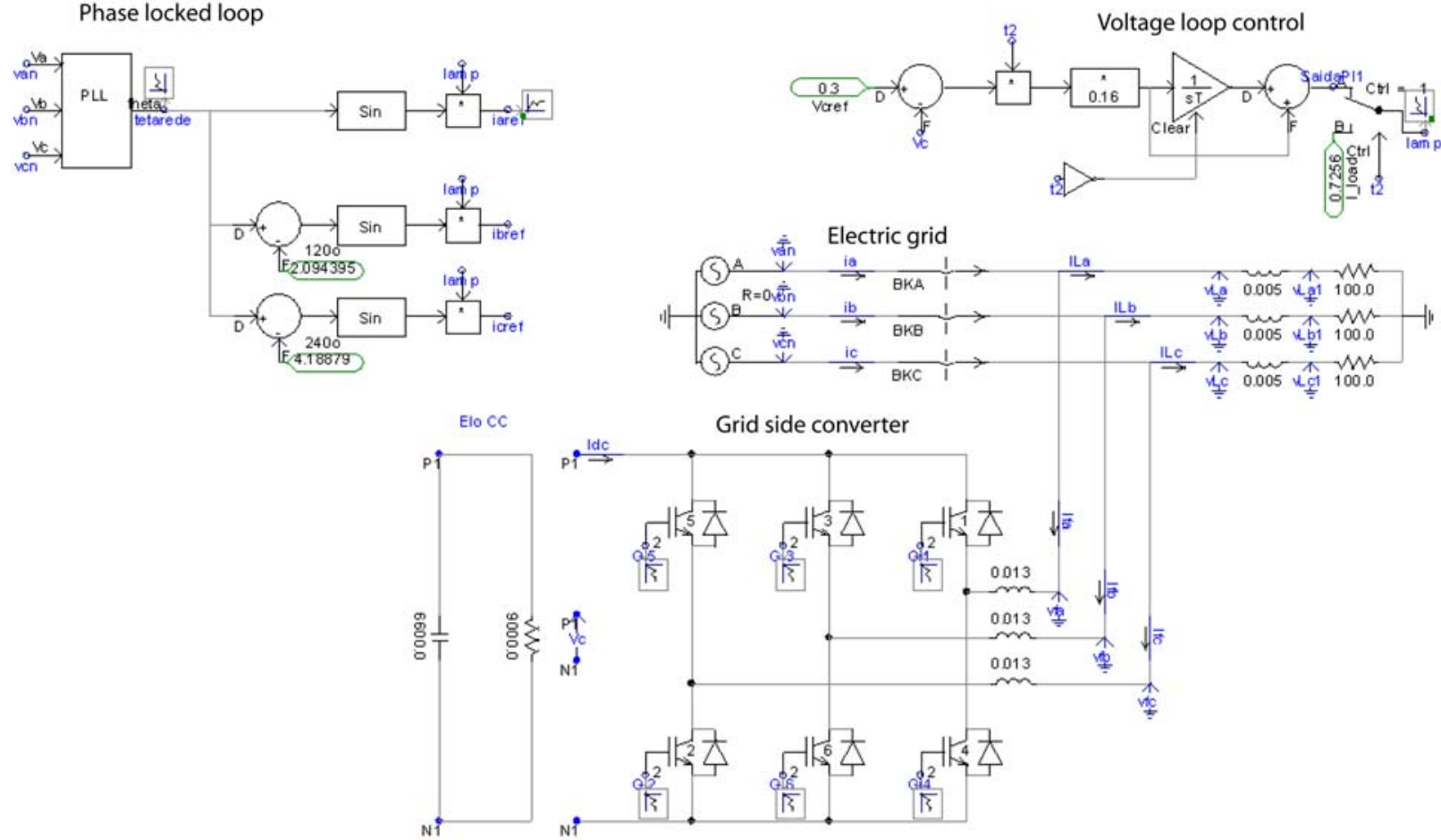

Fig. A2. PSCAD model to represent the electric system and the grid side converter. 